\title{
Frequency and risk factors of severe postoperative bleeding after proctological surgery: a retrospective case-control study
}

\author{
Sarah Taieb ${ }^{1}$, Patrick Atienza ${ }^{1}$, Jean-David Zeitoun ${ }^{1}$, Milad Taouk $^{1}$, Josée Bourguignon ${ }^{1}$, \\ Christian Thomas ${ }^{1}$, Nabila Rabahi ${ }^{1}$, Saliha Dahlouk ${ }^{1}$, Anne-Carole Lesage ${ }^{1}$, David Lobo ${ }^{2}$, Isabelle Etienney ${ }^{1}$ \\ ${ }^{1}$ Proctologic Surgery, Groupe Hospitalier Diaconesses Croix Saint-Simon, Paris; ${ }^{2}$ Anesthesia Department, Groupe Hospitalier Diaconesses \\ Croix Saint-Simon, Paris, France
}

Purpose: The aim of this study was to assess frequency and risk factors of severe bleeding after proctological surgery requiring hemostatic surgery observed after publication of the French guidelines for anticoagulant and platelet-inhibitor treatment.

Methods: All patients who underwent proctological surgery between January 2012 and March 2017 in a referral center were included. Delay, severity of bleeding, and need for blood transfusion were recorded. Patients with severe postoperative bleeding were matched to controls at a 2:1 ratio adjusted on the operator, and the type of surgery.

Results: Among the 8,890 operated patients, $65(0.7 \%)$ needed a postoperative hemostatic procedure in an operating room. The risk of a hemostatic surgery was significantly increased after hemorrhoidal surgery compared with other procedures $\left(1.9 \%\right.$ vs. $\left.0.5 \%, \mathrm{P}<10^{-4}\right)$ and was most frequent after Milligan-Morgan hemorrhoidectomy $(2.5 \%)$. Mean bleeding time was 6.2 days and no bleeding occurred after day 15 . Blood transfusion rate was $0.1 \%$. Treatment with anticoagulants and platelet inhibitors were managed according to recommendations and did not increase the severity of bleeding. The risk of severe bleeding was significantly lower in active smokers vs. non-smokers in univariate $(16.9 \%$ vs. $36.2 \%, \mathrm{P}=0.007)$ and multivariate (odds ratio, $0.31 ; 95 \%$ confidence interval, $0.14-0.65$ ) analysis whereas sex, age, and body mass were not significantly associated with bleeding.

Conclusion: Severe postoperative bleeding occurs in $0.7 \%$ of patients, but varies with type of procedure and is not affected by anticoagulant or antiplatelet treatment. These treatments given in accordance with the new guidelines do not increase the severity of postoperative bleeding.

Keywords: Postoperative hemorrhage; Colorectal surgery; Complications; Morbidity

\section{INTRODUCTION}

Bleeding after hemorrhoidal surgery is a classical postoperative complication but surprisingly the risk of severe bleeding requiring

Received: Feb 17, 2021 - Revised: Apr 22, 2021 - Accepted: May 1, 2021 Correspondence to: Isabelle Etienney, M.D.

Proctologic Surgery, Groupe Hospitalier Diaconesses-Croix Saint Simon, 125 rue d'Avron, 75020 Paris, France

Tel: +33-1-44-64-20-64, Fax: +33-1-44-64-33-17

E-mail: ietienney@hospital-dcss.org

ORCID: https://orcid.org/0000-0002-5941-8589

(C) 2022 The Korean Society of Coloproctology

This is an open-access article distributed under the terms of the Creative Commons Attribution NonCommercial License (https://creativecommons.org/licenses/by-nc/4.0) which permits unrestricted noncommercial use, distribution, and reproduction in any medium, provided the original work is properly cited. second surgery is not well documented for each type of proctological procedure [1-4]. Although intraoperative hemostasis is rarely challenging, acute delayed bleeding, occurring after patients have returned home, could expose to anemia, hypovolemia, and hemorrhagic shock. Previous studies tried to classify the severity of postoperative bleeding based on clinical information and medical condition but the categories described-mild, intermediate, and severe bleeding - are poorly reproducible and morbidity and clinical consequences vary greatly within each category [1].

Though it has been suggested that several factors including the surgeon, the location of the wound, male sex, and dialysis may increase the risk of postoperative bleeding, no risk factor has been clearly identified $[3,5,6]$.

Furthermore, anticoagulant (AC) or platelet-inhibitor (PI) treat- 
ments may increase the risk and the severity of postoperative bleeding. Few data are available concerning the use of ACs or direct thrombin inhibitors (DTI) during these complications. Likewise, little is known about prevention. Two French studies by Pigot et al. in 2011 [1] and 2012 [2] assessed the frequency of hemorrhage after proctological surgery and showed an increased risk of bleeding when oral ACs were stopped and replaced by lowmolecular-weight heparin (LMWH) compared to situations where the oral ACs were continued (23\% vs. $57 \%$ ). These studies suggested an increased risk of bleeding in patients given clopidogrel (relative risk, 10) but not aspirin. In 2012, new guidelines were published by the French National Health Agency (Haute Autorité de Santé, HAS) concerning proctological surgery, changing management practices for PI treatment $[3,4]$.

The aim of this study was to assess the frequency and the risk factors of early and delayed bleeding after proctological surgery needing hemostatic surgery to be controlled, observed after publication of the new HAS guidelines for the management of AC and PI treatments. Use of AC and PI treatments and compliance with the new guidelines were also recorded. Furthermore, we tried to evaluate the potential role of sex as a risk factor for bleeding as suggested by others [3].

\section{METHODS}

\section{Patients}

All patients who underwent scheduled or emergency proctological surgery such as hemorrhoidectomy, hemorrhoidopexy, fissurectomy with or without advancement flaps, tumor resection, surgery for fistula-in-ano or condyloma, performed by 13 practitioners between January 2012 and March 2017 in 1 specialized center were included. Patient age and sex, type of surgery, and surgeon were extracted from the prospective database of all proctological surgical procedures. Instrumental treatment, pilonidal disease, and surgery for sacral nerve stimulation were excluded.

Medical records of all patients needing hemostatic surgery up to 30 days after the initial procedure were analyzed to identify cases. Each identified case was matched with 2 control cases adjusted on type of procedure and surgeon. The control cohort was constructed by selecting the next 2 consecutive patients undergoing the same procedure with the same surgeon. Severity and management of bleeding were assessed. The interval of time from the initial procedure to the first bleeding, hemoglobin level before surgery and at the time of bleeding, and in case of transfusion, the number of packed red blood cell units needed were recorded for all cases. Sex, age, surgeon, body mass index, AC or PI medication, and detailed information about the management of AC or PI treatment during the perioperative period were assessed for cases and controls.

All hemorrhoidectomies were performed with scissors, fissurectomies with scissors and cold blade scalpel and pedicle ligatures were made with resorbable sutures. Resection by electrocautery was used for infected fissures, fistula-in-ano, and condylomas. Hemorrhoidopexies (Longo procedures) were performed with a PPH 03 stapler (Ethicon Endo-Surgery, Cincinnati, OH, USA). The decision to refer to the operative room for hemostatic surgery was based on medical history, clinical data, the surgeon's examination, failure of local hemostatic techniques, and the abundance of blood loss and requirement for blood transfusion.

\section{Ethical considerations}

In compliance with French regulations concerning retrospective studies, an information letter was sent to all patients and a nonobjection statement was obtained.

\section{Statistical analysis}

Quantitative variables were presented as median (interquartile range $[\mathrm{IQR}])$ and compared with Student t-test. A statistically significant difference was taken as $\mathrm{P}<0.05$. The univariate study was based upon Fisher exact test or the Kruskal-Wallis test for continuous variables. Any variable achieving $\mathrm{P}<0.2$ in univariate analysis was retained for the multivariate analysis. For each test, the risk alpha was set at $5 \%$.

\section{RESULTS}

Between January 2012 and May 2017, among 8,990 patients who underwent proctological surgery performed by 13 surgeons, $0.7 \%$ (65 of 8,990) required second surgery within 30 days for postoperative bleeding. The frequency of severe postoperative bleeding varied significantly with the type of procedure from $2.5 \%$ after Milligan-Morgan hemorrhoidectomy (38 of 1,519) to $0.3 \%$ after procedures without hemorrhoidal suture (Table 1). Hemorrhoidopexy and hemorrhoidal procedures limited to 1 pedicle had an intermediate risk of bleeding (1.1\% [ 1 of 87] and $0.8 \%$ [7 of 866] respectively). We did not observe any difference between low and complex fistulas. Blood transfusion was required in $0.1 \%$ of cases (9 of 8,990) mainly after Milligan-Morgan procedures (7 of 9) accounting for nearly $0.5 \%$ of all Milligan-Morgan procedures (7 of 1,519) $(\mathrm{P}=0.001)$.

The median time interval between the surgery and the bleeding was 6.2 days (IQR, 3-9 days) and no bleeding was reported after day 15 (Fig. 1). Most of the bleeding episodes occurred on postoperative days 7 and 8 , but $23.1 \%$ of patients (15 of 65) bled during the first 2 days after surgery so that $76.9 \%$ of the severe bleeding cases (50 of 65) occurred after the patient had returned home. Fifty percent of severe bleedings occurred before day 7 and $97 \%$ before day 13 (Fig. 1).

Hemorrhage was due to venous bleeding in $43.1 \%$ of cases $(28$ of 65), arterial bleeding in $40.0 \%$ (26 of 65) or was due to a weak suture of the hemorrhoidal pedicle in $16.9 \%$ (11 of 65). Hemoglobin level decreased by $2.8 \mathrm{~g} / \mathrm{dL}(0.6-4.6 \mathrm{~g} / \mathrm{dL})$ between the initial procedure and hemostatic surgery, and by $2.45 \mathrm{~g} / \mathrm{dL}$ after Milligan-Morgan procedures. Nine patients $(13.8 \%)$ needed blood 
Table 1. Prevalence of bleeding according to surgical proctological procedure

\begin{tabular}{|c|c|c|c|c|}
\hline Variable & Total population $(n=8,990)$ & Case $(n=65)$ & Bleeding prevalence (\%) & Transfusion \\
\hline Total & & & 0.7 & $9(0.1)$ \\
\hline Hemorrhoidal surgery & $2,472(27.5)$ & $46(70.8)$ & $1.8^{\mathrm{a}}$ & $7(0.3)$ \\
\hline Milligan-Morgan & $1,519(16.9)$ & $38(58.5)$ & 2.5 & $7(0.5)$ \\
\hline Single pile excision & $866(9.6)$ & $7(10.8)$ & 0.9 & $0(0)$ \\
\hline Longo & $87(1.0)$ & $1(1.5)$ & 1.1 & $0(0)$ \\
\hline Fissure & $1,062(11.8)$ & $5(7.7)$ & $0.5^{\mathrm{a}}$ & $1(0.1)$ \\
\hline Fissurectomy & $294(3.3)$ & $3(4.6)$ & 1.0 & \\
\hline Advanced flap & $768(8.5)$ & $2(3.1)$ & 0.2 & \\
\hline Condyloma & $1,535(17.1)$ & $4(6.2)$ & $0.3^{\mathrm{a}}$ & $0(0)$ \\
\hline Fistula & $3,776(42.0)$ & $10(15.4)$ & $0.3^{\mathrm{a}}$ & $1(0.03)$ \\
\hline Complex fistula & $3,028(33.7)$ & $6(9.2)$ & 0.2 & \\
\hline Simple fistula & $748(8.3)$ & $4(6.2)$ & 0.5 & \\
\hline Others ${ }^{b}$ & $145(1.6)$ & $0(0)$ & $0(0)$ & $0(0)$ \\
\hline
\end{tabular}

Values are presented as number (\%) or percentage only.

ap $<10^{-4}$, comparing severe bleeding rates between the hemorrhoidal surgery and the other procedures. ${ }^{\text {}}$ Sphincter repair, under general anesthesia examination, artificial sphincter placement, rectal tumor resection.

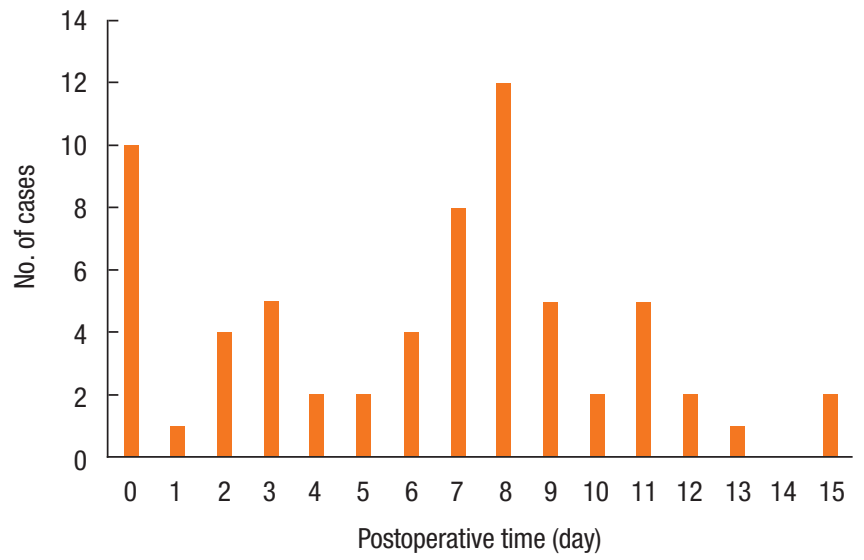

Fig. 1. Number of cases according to the time after surgery.

transfusions ( 1 to 4 packed red blood cell units); after day 7 for 6 of 9 (66.7\%) (Fig. 2) and after Milligan-Morgan procedure for 7 of $9(77.8 \%)$.

Seven of 65 patients $(10.8 \%)$ needed more than one hemostatic surgery: 3 patients underwent 3 operations, 4 patients underwent 2 operations ( 1 of them had factor XI deficiency); 3 of the 7 had Milligan-Morgan hemorrhoidectomy.

Among the 65 patients who underwent and hemostatic surgery, 3 received $\mathrm{ACs}$ (rivaroxaban and vitamin $\mathrm{K}$ antagonist). In all cases, oral ACs were stopped 5 days before surgery and replaced by LMWH that was continued 2 weeks after surgery. The first patient, on rivaroxaban for cardiac arrhythmia, underwent a Milligan-Morgan procedure and needed hemostatic surgery on day 9 , with no need for transfusion despite a $3 \mathrm{~g} / \mathrm{dL}$ drop in hemoglobin

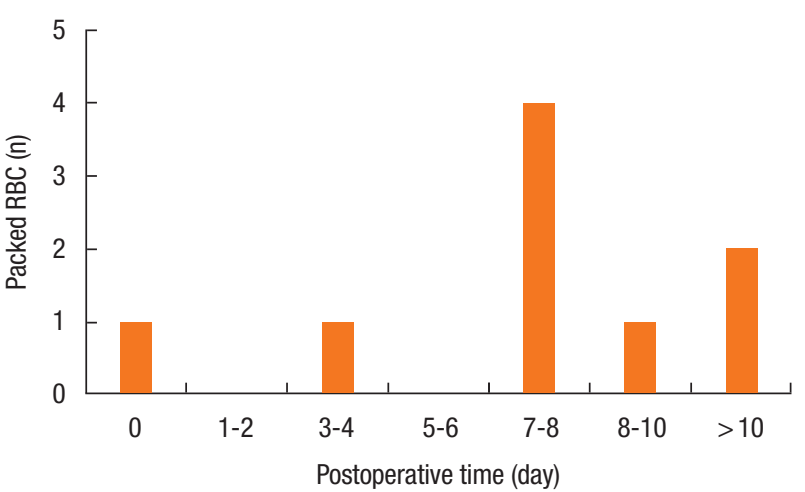

Fig. 2. Number of packed red blood cell (RBC) units according to the time after surgery.

level. The second patient, taking rivaroxaban for cardiac arrhythmia, underwent fissurectomy and needed hemostatic surgery on day 3 with no need for transfusion. The third patient was taking vitamin $\mathrm{K}$ antagonist for a cardiac valve and underwent a Milligan-Morgan procedure; hemostatic surgery was indicated on day 3 with transfusion of 2 packed red blood cell units for a $5.3 \mathrm{~g} / \mathrm{dL}$ drop in hemoglobin.

Among the 65 cases, 2 patients had hemophilia (factor XI deficiency and mild hemophilia A), bled respectively on day 12 and 10 , and needed factors or plasma transfusion for the factor XI deficiency. In addition, 2 patients in the case group received PI medication (aspirin) but none was on clopidogrel. AC and PI treatments were managed according to the new recommendations and did not increase the severity of bleeding; there was no 
difference in the interval from the initial procedure to bleeding, the number of packed red blood cell units needed, or loss of hemoglobin between patients given or not AC or PI. Comparing to adjusted cases, AC or PI treatment was not associated with a risk of severe bleeding and reintervention for a hemostatic procedure (Table 2).

Table 2. Characteristics of cases and controls

\begin{tabular}{|c|c|c|c|}
\hline Characteristic & $\begin{array}{l}\text { Case } \\
(n=65)\end{array}$ & $\begin{array}{c}\text { Control } \\
(n=130)\end{array}$ & P-value \\
\hline Age (yr) & $47.0 \pm 23.3$ & $45.5 \pm 24.0$ & 0.98 \\
\hline \multicolumn{4}{|l|}{ Sex } \\
\hline Male & $48(73.8)$ & $74(56.9)$ & 0.03 \\
\hline Female & $17(26.2)$ & $56(43.1)$ & \\
\hline Past history of anal surgery & $2(3.1)$ & $7(5.4)$ & 0.47 \\
\hline \multicolumn{4}{|l|}{ Smoking status } \\
\hline Non-smoker & $54(83.1)$ & $83(63.9)$ & 0.007 \\
\hline Smoker & $11(16.9)$ & 47 (36.2) & \\
\hline \multicolumn{4}{|l|}{ Body mass index $\left(\mathrm{kg} / \mathrm{m}^{2}\right)$} \\
\hline$<25$ & $45(69.2)$ & $82(63.1)$ & 0.43 \\
\hline$\geq 25$ & $20(30.8)$ & $48(36.9)$ & \\
\hline HIV-positive & $2(3.1)$ & $11(8.5)$ & 0.23 \\
\hline Liver disease & $1(1.5)$ & $1(0.8)$ & $>0.99$ \\
\hline Hemophilia & $2(3.1)$ & $0(0)$ & 0.11 \\
\hline \multicolumn{4}{|l|}{ Anticoagulant } \\
\hline No & $62(95.4)$ & $127(97.7)$ & 0.33 \\
\hline Yes & $3(4.6)$ & $3(2.3)$ & \\
\hline \multicolumn{4}{|l|}{ Antiplatelet agent } \\
\hline No & $63(96.9)$ & $127(97.7)$ & 0.87 \\
\hline Yes & $2(3.1)$ & $3(2.3)$ & \\
\hline \multicolumn{4}{|l|}{ Dialysis } \\
\hline No & 65 (100) & $130(100)$ & \\
\hline Yes & $0(0)$ & $0(0)$ & NA \\
\hline
\end{tabular}

Values are presented as data only or number (\%).

HIV, human immunodeficiency virus; NA, not available.
The proportion of male patients with severe postoperative bleeding $(73.8 \%)$ was higher than in the control group and during the study period, male sex predominated (65.2\%). In multivariate analysis, male sex was associated with an increased risk of severe bleeding (odds ratio [OR], 2.44; 95\% confidence interval [CI], 1.25-4.98; $\mathrm{P}=0.01)$.

There was no difference in postoperative bleeding according to body mass index. The risk of severe bleeding was significantly lower in active smokers at $16.9 \%$ (11 of 65 ) vs. $36.2 \%$ in nonsmokers or former smokers in univariate ( 47 of $130, \mathrm{P}=0.007)$ and in multivariate analysis (OR, 0.31; 95\% CI, 0.14-0.65) (Table 3).

\section{DISCUSSION}

Our study evaluates the frequency of severe bleeding requiring hemostatic surgery occurring within 30 days after proctological surgery at $0.7 \%$ for all procedures but shows clearly that the risk is increased in procedures with hemorrhoidal suture, and particularly Milligan-Morgan hemorrhoidectomy for which the prevalence was $2.5 \%$ prevalence with a statistically increased need for transfusion. This frequency is consistent with other published data $[1,3,5-7]$ on severe hemorrhage.

Controlling bleeding is challenging since hemorrhoidal surgery is mainly functional. Various treatments designed to reduce the risk of hemorrhage after surgery have been described; e.g., venotonic agents [8] that have not shown significant efficacy, or anal tampons that do not reduce bleeding after surgery but do increase postoperative pain significantly [9].

In our cases, hemorrhage occurred on average 6.2 days after surgery, which is consistent with other data in the literature $[1,10$ 12]. However, the day-by-day analysis shows 2 peaks of frequency, a first peak during the operative day, then a second one around postoperative days 7 and 8, suggesting different causes or mechanisms of bleeding would be involved. We found that early bleeding was less frequent and abundant, and so might have a venous origin. Hemorrhages that occurred between days 6 and 8 were more severe and required more blood transfusions, corresponding to the classical delayed arterial bleeding after pedicle excision. This could be explained by local trauma caused by constipation related to excessive pain medication or hard stools. In this situa-

Table 3. Univariate and multivariate analysis of factors associated with severe bleeding

\begin{tabular}{|c|c|c|c|c|c|}
\hline \multirow{2}{*}{ Variable } & \multicolumn{3}{|c|}{ Univariate analysis } & \multicolumn{2}{|c|}{ Multivariate analysis } \\
\hline & Case & Control & P-value & OR $(95 \% \mathrm{Cl})$ & P-value \\
\hline Active smoking & $16.9 \%$ & $36.2 \%$ & 0.007 & $0.31(0.14-0.65)$ & 0.003 \\
\hline Male sex & $73.8 \%$ & $56.9 \%$ & 0.030 & $2.44(1.25-4.98)$ & 0.010 \\
\hline $\mathrm{AC}$ or $\mathrm{PI}$ & $7.7 \%$ & $4.6 \%$ & 0.370 & $\mathrm{Nl}$ & $\mathrm{NI}$ \\
\hline Age $(y r)^{a}$ & $45.6(12.0)$ & $46.0(13.0)$ & 0.980 & $\mathrm{NI}$ & $\mathrm{NI}$ \\
\hline
\end{tabular}

$\mathrm{OR}$, odds ratio; $\mathrm{Cl}$, confidence interval; $\mathrm{AC}$, anticoagulant; PI, platelet-inhibitor; NI, not included.

aMedian (interquartile range). 
tion, the hemorrhage is severe, with a risk of hypovolemia, and particularly challenging since the patient has often returned home. In our series, the average drop in hemoglobin level from before proctological surgery to admission for severe hemorrhage was $2.8 \mathrm{~g} / \mathrm{dL}$, with $50 \%$ of patients having lost more than $2 \mathrm{~g} / \mathrm{dL}$. Moreover, this lower hemoglobin level does not reflect the hemoconcentration effect resulting from loss of blood volume nor the hemodilution effect of any fluid filling ongoing at time blood samples are drawn. Consequently, postoperative bleeding is a very serious complication requiring emergency management by an experienced hospital team.

The risk of postoperative bleeding was low after fissurectomy, fistulectomy, and condyloma surgery. The rate of transfusion was very low (less than $0.01 \%$ ). In these patients without any previous postoperative bleeding or ongoing treatment, a systematic biological sample may not be cost-effective [13]. We purposely separated patients who underwent fissurectomy into 2 categories (with or without flap) because fissurectomy with an advancement flap is commonly performed with a blade causing little bleeding, the fissurectomy being achieved with diathermy cutting, especially in case of infected fissures. Although we performed more fissurectomy procedures with advanced flap we did not have more early or delayed hemorrhages compared to fissurectomies without flap.

Our study was not designed to assess the risk of postoperative bleeding in patients treated by AC and PI because we did not know the frequency of these treatments in the whole operated population. However, we found that treatment with AC and PI was managed in compliance with the new French guidelines. Moreover, the control cases showed that AC and PI did not increase the severity of bleeding, which is a very important finding. Pigot et al. [1] suggested in 2011 that using this management scheme for AC treatments would increase the risk of postoperative bleeding. Today the discussion about perioperative management of AC and PI is more focused on the thromboembolic risk of discontinuation rather than bleeding. The lack of prospective studies assessing the effect of continuing AC treatments (either vitamin $\mathrm{K}$ antagonists or DTI) or of introducing LMWH perioperatively proscribes any conclusion. Continuing PI is more consensual and, in our study, PIs were continued according to the guidelines in all operated patients, without any increase in bleeding severity.

Knowing more about potential risk factors would be helpful for patients and practitioners. In a prospective study assessing 4,880 hemorrhoidectomy patients, the rate of hemorrhage after surgery was $0.9 \%$ and the multivariate analysis showed that the surgeon and male sex were independent risk factors [14]. Although the proportion of males was higher in the operated population, our study confirms the male sex as risk factor for severe postoperative bleeding. The reasons why the male sex would be a risk factor for severe postoperative bleeding remain unclear. We did not analyze a potential surgeon effect because known variables (age, experience, activity in our center) were too divergent for valid comparisons.
We found that smoking could be a protector factor against severe hemorrhages. A few studies have shown that smoking is deleterious for wound healing either in terms of length or quality of the healing $[15,16]$. This characteristic was not evaluated in our study. One hypothesis could be that a decrease in the local microcirculation due to smoking-induced vasoconstriction might limit bleeding at the early phase after surgery, the effect of smoking becoming more deleterious later on.

A medical history of prior proctological surgery did not seem to be a risk factor of postoperative bleeding in our study. Little is known about this issue and the medical literature has little data although one recent study suggested that previous history of anal surgery was highly associated with the risk of anal fistula [17].

Our study was not designed to evaluate the frequency of all postoperative bleedings regardless of the severity. We focused on patients with severe bleeding leading to a medical decision to reintervene. This could be criticized as an endpoint but it is clinically pertinent and allowed us to identify all patients who underwent a surgical procedure in our hospital. The retrospective design of our study could be a bias possibly leading to underestimating the frequency of severe hemorrhages if patients were reoperated in another center. Only a systematic prospective study could evaluate the true frequency of severe or nonsevere postoperative hemorrhages.

In conclusion, Milligan-Morgan hemorrhoidectomy remains a risky surgery in terms of severe postoperative bleeding; a second surgical hemostatic procedure being required for $2.5 \%$ of patients and a transfusion for $0.5 \%$. There is an intermediary risk of severe bleeding after hemorrhoidopexy and single pedicle excision, whereas the risk is lower for procedures without hemorrhoidal suture, so that adequate preoperative management may not require systematic blood samples. Furthermore, ACs or PIs do not increase the severity of bleeding when given during the perioperative period in compliance with guidelines. The benefits of continuing PIs during proctological surgery are probably greater than the benefits of discontinuation.

In our case-control series, smoking seemed to have a protective effect against postoperative bleeding. Prospective studies are necessary to investigate further the role of smoking. We were unable to demonstrate any other risk factors. Indeed, knowing more about potential risk factors would be helpful for patients and practitioners.

\section{CONFLICT OF INTEREST}

No potential conflict of interest relevant to this article was reported.

\section{FUNDING}

None. 


\section{ORCID}

Sarah Taieb, https://orcid.org/0000-0001-8166-042X

Isabelle Etienney, https://orcid.org/0000-0002-5941-8589

\section{ACKNOWLEDGMENTS}

The authors thank Kevin Zuber for his support in the statistical analysis.

\section{REFERENCES}

1. Pigot F, Juguet F, Bouchard D, Castinel A, Vove JP. Prospective survey of secondary bleeding following anorectal surgery in a consecutive series of 1,269 patients. Clin Res Hepatol Gastroenterol 2011; 35:41-7.

2. Pigot F, Juguet F, Bouchard D, Castinel A. Do we have to stop anticoagulant and platelet-inhibitor treatments during proctological surgery? Colorectal Dis 2012;14:1516-20.

3. Chen HH, Wang JY, Changchien CR, Chen JS, Hsu KC, Chiang JM, et al. Risk factors associated with posthemorrhoidectomy secondary hemorrhage: a single-institution prospective study of 4,880 consecutive closed hemorrhoidectomies. Dis Colon Rectum 2002;45:1096-9.

4. Haute Autorité de santé (HAS). Antiagrégants plaquettaires: prise en compte des risques thrombotique et hémorragique lors des actes invasifs de proctologie chez le coronarien [Internet]. Saint-Denis La Plaine Cedex: HAS; 2012 [cited 2021 May 2]. Available from: https:// www.has-sante.fr/upload/docs/application/pdf/2012-10/recommandations_antiagregant_plaquettaire.pdf.

5. Bouchard D, Abramowitz L, Castinel A, Suduca JM, Staumont G, Soudan D, et al. One-year outcome of haemorrhoidectomy: a prospective multicentre French study. Colorectal Dis 2013;15:719-26.
6. Yano T, Matsuda Y, Asano M, Kawakami K, Nakai K, Nonaka M, et al. The outcome of postoperative hemorrhaging following a hemorrhoidectomy. Surg Today 2009;39:866-9.

7. Chen HH, Wang JY, Changchien CR, Yeh CY, Tsai WS, Tang R. Effective management of posthemorrhoidectomy secondary hemorrhage using rectal irrigation. Dis Colon Rectum 2002;45:234-8.

8. Ho YH, Foo CL, Seow-Choen F, Goh HS. Prospective randomized controlled trial of a micronized flavonidic fraction to reduce bleeding after haemorrhoidectomy. Br J Surg 1995;82:1034-5.

9. Langenbach MR, Chondros S, Sauerland S. Tamponade dressings may be unnecessary after haemorrhoidectomy: a randomised controlled clinical trial. Int J Colorectal Dis 2014;29:395-400.

10. Kunitake H, Poylin V. Complications following anorectal surgery. Clin Colon Rectal Surg 2016;29:14-21.

11. Hyman N, O'Brien S, Osler T. Outcomes after fistulotomy: results of a prospective, multicenter regional study. Dis Colon Rectum 2009; 52:2022-7.

12. Rosen L, Sipe P, Stasik JJ, Riether RD, Trimpi HD. Outcome of delayed hemorrhage following surgical hemorrhoidectomy. Dis Colon Rectum 1993;36:743-6.

13. Molliex S, Pierre S, Bléry C, Marret E, Beloeil H. Routine preinterventional tests. Ann Fr Anesth Reanim 2012;31:752-63.

14. Lee KC, Liu CC, Hu WH, Lu CC, Lin SE, Chen HH. Risk of delayed bleeding after hemorrhoidectomy. Int J Colorectal Dis 2019; 34:247-53.

15. Ahn C, Mulligan P, Salcido RS. Smoking-the bane of wound healing: biomedical interventions and social influences. Adv Skin Wound Care 2008;21:227-36.

16. Guo S, Dipietro LA. Factors affecting wound healing. J Dent Res 2010;89:219-29.

17. Assaraf J, Lambrescak E, Lefèvre JH, de Parades V, Bourguignon J, Etienney I, et al. Increased long-term risk of anal fistula after proctologic surgery: a case-control study. Ann Coloproctol 2021;37:90-3. 